\title{
CT Lesion Model-Based Structural Allografts: Custom Fabrication and Clinical Experience
}

\author{
Jan Claas Brune ${ }^{a} \quad$ Uwe Hesselbarth $^{\mathrm{a}}$ Philipp Seifert \\ Mark David Smith ${ }^{\mathrm{a}}$ Dirk Seifert ${ }^{\mathrm{d}}$ \\ a Deutsches Institut für Zell- und Gewebeersatz gGmbH, Berlin, \\ ${ }^{\mathrm{b}}$ Institut für Rechtsmedizin, Universitätsklinikum Hamburg-Eppendorf, \\ ${ }^{c}$ V V C von Versen International Consultants, Wandlitz, \\ ${ }^{\mathrm{d}}$ Robert-Koch-Krankenhaus Apolda GmbG, Apolda, Germany
}

Dimitri Nowack ${ }^{\mathrm{b}}$

Rüdiger von Versen ${ }^{c}$

\section{Keywords}

X-ray computed tomography $\cdot$ X-ray CT .

Individualised medicine - Customised transplant .

Bone transplantation - Allograft

\section{Summary}

Background: Patients requiring knee and hip revision arthroplasty often present with difficult anatomical situations that limit options for surgery. Customised mega-implants may be one of few remaining treatment options. However, extensive damage to residual bone stock may also be present, and in such cases even customised prosthetics may be difficult to implant. Small quantities of lost bone can be replaced with standard allografts or autologous bone. Larger defects may require structural macro-allografts, sometimes in combination with implants (allograft-prosthesis composites). Methods: Herein, we describe a process for manufacturing lesionspecific large structural allografts according to a 3D, fullscale, lithographically generated defect model. These macroallografts deliver the volume and the mechanical stability necessary for certain complex revisions. They are patientand implant-matched, negate some requirements for additional implants and biomaterials and save time in the operating theatre by eliminating the requirement for intra-operative sizing and shaping of standard allografts. Conclusion: While a robust data set from long-term follow-up of patients receiving customised macro-allografts is not yet available, initial clinical experience and results suggest that lesion-matched macro-allografts can be an important component of revision joint surgery.

\section{Schlüsselwörter}

Röntgen-Computertomographie · Röntgen-CT . Individualisierte Medizin - Transplantat-Sonderanfertigungen . Knochentransplantation - Allogenes Transplantat

\section{Zusammenfassung}

Hintergrund: Der Revisionsarthroplastik im Hüft- und Kniegelenk liegt häufig eine komplexe anatomische Defektsituation zugrunde, welche die Möglichkeiten der chirurgischen Behandlung einschränkt. Spezielle und teilweise aufwändig produzierte Sonderanfertigungen von Endoprothesen sind dann oft eine der wenigen Behandlungsmöglichkeiten. Ausgedehnte Knochendefekte können die Implantation hochspezifischer Prothesen zusätzlich erschweren. Während kleinere Defekte mit Standardprodukten (Knochengranulate/-chips) oder autologem Knochenmaterial gefüllt werden können, konkurrieren für die Wiederherstellung größerer Knochendefekte strukturelle Knochengewebetransplantate (auch in Kombination mit Implantaten) mit Metallaugmentationen. Methoden: In dem nachfolgenden Artikel wird der Prozess des Designs und der Herstellung von strukturellen Knochengewebetransplantaten basierend auf der computertomographischen Erfassung des Knochendefekts beschrieben. Solche Transplantate ermöglichen den Ersatz der verlorenen Knochenbasis sowie die Wiederherstellung der mechanischen Stabilität in schwierigen Revisionssituationen. Als Sonderanfertigungen sind diese Transplantate optimal an die Anatomie des Patienten und an eventuell ko-transplantiertes Prothesenmaterial angepasst. Dank dieser Punkte kann die Dauer der Operation deutlich verkürzt werden, da ein intraoperatives Anpassen von Standardprodukten sowie eine Entnahme autologen Materials entfällt. Schlussfolgerung: Erste klinische Erfahrungen zeigen, dass defektbasierte Sonderanfertigungen von Makrotransplantaten einen wichtigen Platz unter den Behandlungsmöglichkeiten bei Revisionsarthroplastiken besetzen können. Die Ergebnisse der bisher beobachteten Langzeitverläufe sind vielversprechend, bedürfen aber einer Verifizierung durch weitere klinische Daten.

\section{KARGER \\ Fax +497614520714 \\ Information@Karger.de}

www.karger.com (c) 2012 S. Karger GmbH, Freiburg

$1660-3796 / 12 / 0396-0395 \$ 38.00 / 0$

Accessible online at:

www.karger.com/tmh 


\section{Introduction}

The number of primary hip and knee replacement operations continues to increase as the indications broaden and the average life expectancy of patients and their demand for activity increase [1]. Between 2003 and 2008 there was a concomitant increase in revision arthroplasty. During this time, the number of knee revisions increased by a factor of 2.24 and that of hip revisions by a factor of 3.4 (fig. 1a,b).

Moreover, multiple (third and even fourth) revisions of implanted prosthetic joints are becoming routine surgical assignments. These cases may be associated with major bone defects as a consequence of previous surgery and/or extensive age and/or disease-related degeneration $[2,3]$. Specialised endoprosthetic components can be used to treat many types of defects. However, when bone loss becomes extensive, alternative treatments such as custom implants, allograft augmentation, or combinations of custom implants and allografts (allograft-prosthesis composites) may become necessary [1, 4-6]. As a consequence, surgeons and manufacturers of implants and transplants are facing new challenges.

The custom manufacture of total hip (THA) and total knee arthroplasty (TKA) implants is becoming commonplace. Endoprosthesis manufacturers already provide patient-specific implant services. However, the cost-benefit ratio of customised implants is still under discussion. Significant differences in clinical outcomes between standard and custom implants have been shown to be either non-existent or are only found in specific clinical settings or within individual clinics $[7,8]$.

However, recent data suggest that custom implants improve outcome in young patients after a 15-year follow-up [9]. Furthermore, custom-made cement-less components in THA for patients with skeletal dysplasia had lower revision and complication rates with comparable function and higher midterm survival [10].

Bone allografts are generally indicated in, but not limited to situations including bone replacement during endoprosthetic surgery, post-traumatic bone defects, bone tumour surgery, osteotomy or as allograft-prosthesis composites.

While the demand for standard allogeneic bone grafts is high, custom manufacture of structural bone allografts is not well established. Possible reasons include the limited availability of donated tissue and the time-consuming manufacturing process. In contrast to medical device companies, among those tissue banks with the necessary approvals most do not yet have the necessary infrastructure or expertise to offer reliable custom transplant manufacturing services.

Nevertheless, the combination of lesion model-based soft tissue and bone allograft components with standard and/or individualised revision prosthetic products offers patientspecific therapeutic options in situations that are otherwise often associated with unsatisfactory clinical outcomes. In both revision THA and revision TKA structural allografts are a valuable alternative to standard treatment options such as in- a

$\begin{array}{lccc}\text { Hip } & 2003 & 2008 & \text { Factor } \\ \text { Primary } & 91551 & 156882 & 1.71 \\ \text { Revision } & 6485 & 22631 & 3.40 \\ & & & \\ \text { Knee } & & & \\ \text { Primary } & 70850 & 146051 & 2.06 \\ \text { Revision } & 4644 & 10387 & 2.24\end{array}$

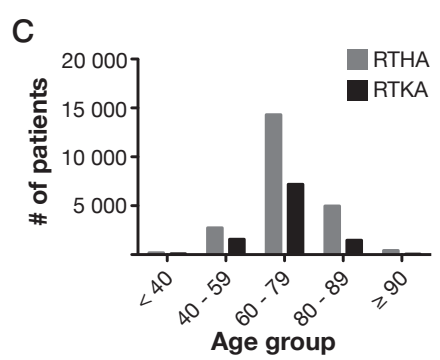

b

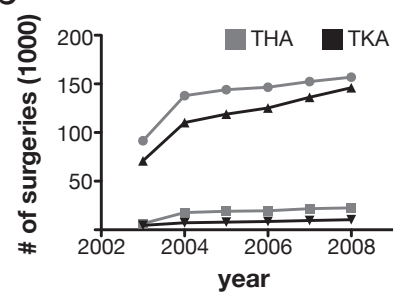

d

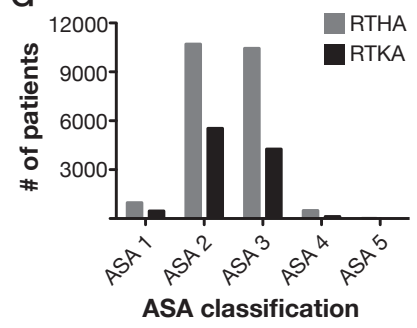

Fig. 1. General data on primary and revision total joint replacement in hip and knee. a Number of operations in 2003 and 2008. The number of total hip arthroplasty (RTHA) and total knee arthroplasty (RTKA) revision operations increased by a factor of 3.4 and 2.24 respectively. b 5-year course of hip and knee primary and revision surgeries. c Age distribution of patients that had revision total hip or knee arthroplasty in 2008. d Classification of patients that had RTHA or RTKA in 2008 according to the classification system of the American Society of Anesthesiologists. (Source: BQS Institut für Qualität und Patientensicherheit).

creased resection or component shift, cement or cement and screw reconstruction, metal prosthetic augmentation or impaction grafting [11-13]. For revision TKA, it has been shown, that early results of structural allografts are similar to those of standard metal augmentation [14].

Further studies have been performed to test allograftprosthesis composites in the reconstruction of the humerus after tumour resection, for the reconstruction of the proximal tibia $[15,16]$ and for total elbow arthroplasty [17-19]. Among the advantages in using structural allografts are the availability of capsular soft tissue attachments with which to reconstruct the salvaged host soft tissues (as demonstrated in the second case study, see below). Potential disadvantages include a higher risk of infection, re-fracture and non-union [20], but the combination of structural allograft and prosthesis may enable each component to provide specific advantages. The allograft can supply soft tissue tendinous and capsular attachment possibilities whilst use of a prosthetic joint can negate articular degeneration and sub-chondral collapse [20]. In a study analysing function and survival in a comparison of allograft-prosthesis composites and mega-prostheses in proximal femoral reconstruction [21], significant differences could not be demonstrated. In this indication, allograftimplant combinations appear to be a viable alternative to mega-implants.

The use of structural allografts is indicated in situations where the bone stock present is not sufficient for reliable implantation of endoprostheses or in settings where the im- 


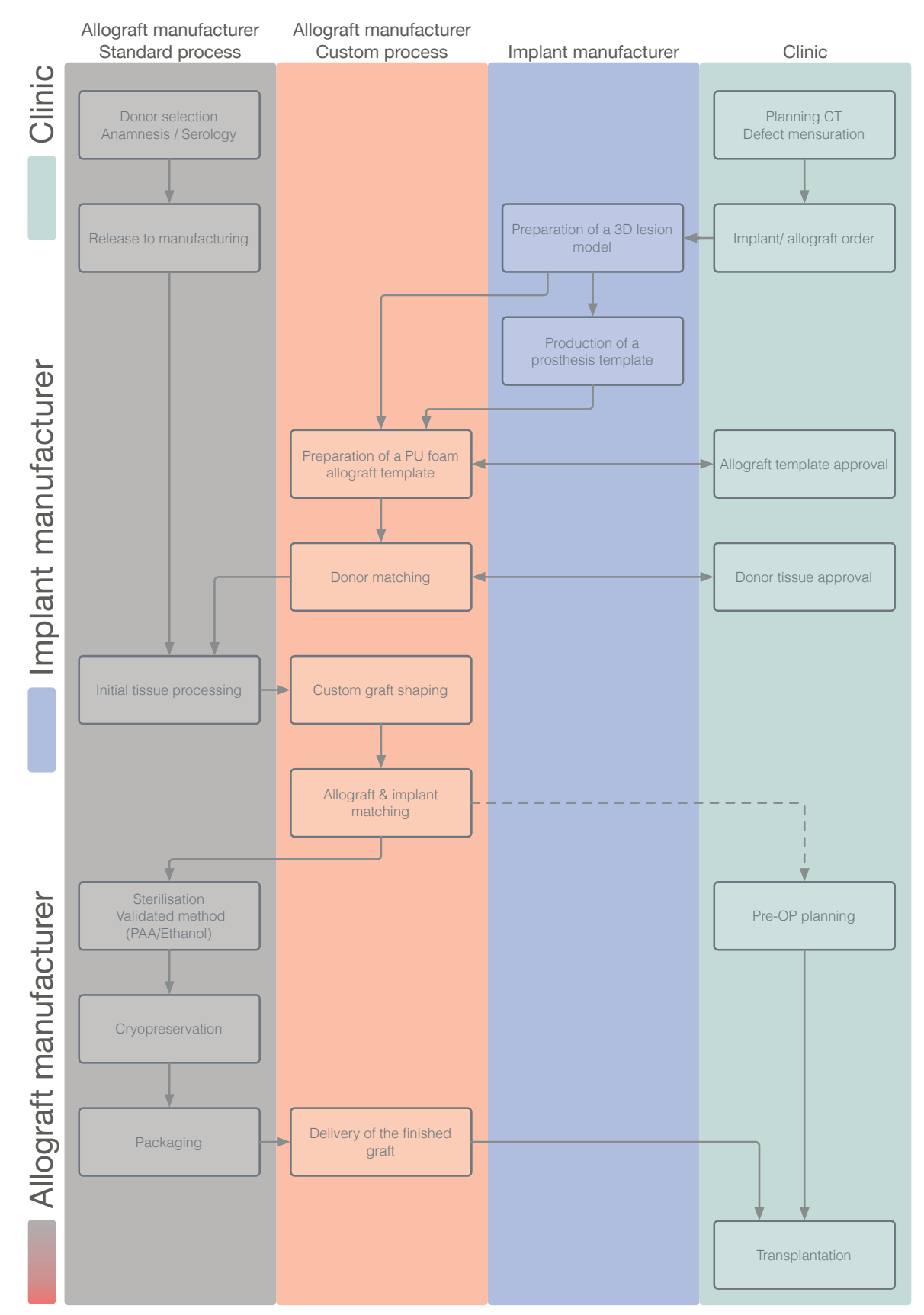

Process flow chart with swim lanes for clinic, implant manufacturer and allograft manufacturer.

provement of bone stock is necessary for likely revisions [22]. In these situations allografts allow reconstruction for sizeable defects [23, 24]. Moreover, for patients with a life expectancy exceeding 10 years, a structural bone graft may be preferable since restoration of bone stock is desirable [25].

Babis and co-workers [3] presented statistics about the long-term function of allograft-prosthesis composites. At 2, 5 and 10 years post operation the percentage of intact, functional implant/transplant combinations was 93, 78 and 69 respectively. This is comparable with other reported data $(65-$ $86 \%$ ) at 10 years [3]. The study identified pre-operative bone loss, the number of previous hip revisions exceeding two and the length of the allograft used as statistically significant modulators of outcome.

The decision to treat a patient with a custom implant and an individual macro-allograft confronts the surgeon, the implant manufacturer and the allograft manufacturer with significant logistical challenges that can only be met when the individual players collaborate closely from the outset. Such a collaboration is also required to deliver the high level of inter-component precision that is a prerequisite for a successful outcome. Matching the allograft to the bone is described as one of the problems associated with the use structural macro-allografts [3]. This can be solved by custom 

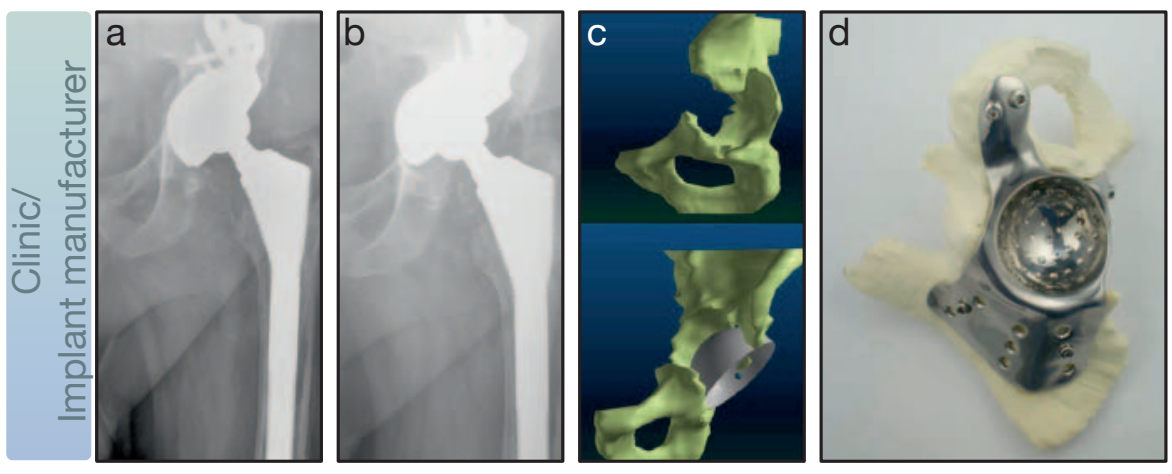

Fig. 3. Revision total hip arthroplasty: 62-yearold male patient with artificial left hip after multiple revisions. a Post-operative radiograph of a previous acetabular component revision. b Acetabular component loosening 15 months after revision. c Virtual 3D planning model for the surgery. d Lateral view of the physical model with the custom implant attached. e Medial view of the physical model with the custom implant attached. The large acetabular defect is visible. $\mathbf{f}$ Photographs from the early stage of allograft template fabrication. $\mathbf{g}$ Allograft template nested in the physical model of the defect. The socket later to hold the acetabluar component of the implant is visible. $\mathbf{h}$ Projection lines show the delineation of the two parts later to be produced from two donor bone blocks of the proximal tibia. i Initial preparation of a proximal donor tibia. $\mathbf{j}-\mathbf{k}$ The individual allograft components interlock with a dovetail (j early shaping, $\mathbf{k}$ final allograft). 1 The allograft positioned in the physical defect model, confirming fit prior to sterilisation. m Intra-operative check of allograft to implant fit, $\mathbf{n}$ Post-operative X-ray.
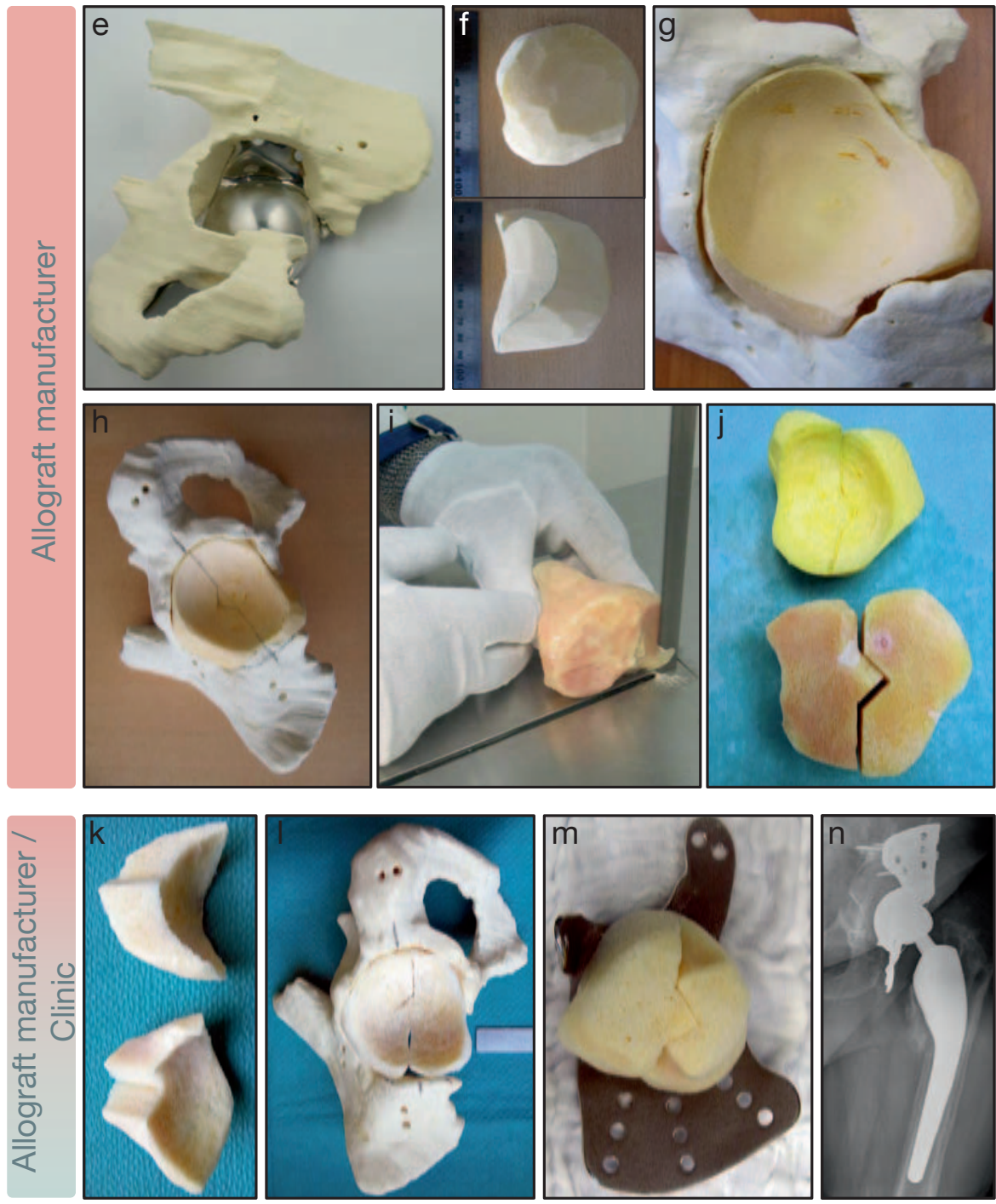

preparation and manufacturing. This article describes a procedure for specifying and manufacturing lesion-specific allografts for complex primary and revision arthroplasty within the German regulatory environment. Six patients have been treated at the Robert Koch Clinic (Apolda, Germany) using structural macro-allografts, custom manufactured at DIZG gGmbH (Berlin, Germany). Two of these cases are reported in detail.

\section{Material and Methods}

This section provides a general overview of the complete custom allograft process from diagnosis to transplantation. A diagrammatic representation of the process is provided in figure 2 .

Informed consent was obtained from all patients prior to treatment.

\section{Diagnosis and Planning}

Patients requiring a joint implant revision and for whom such surgery is 

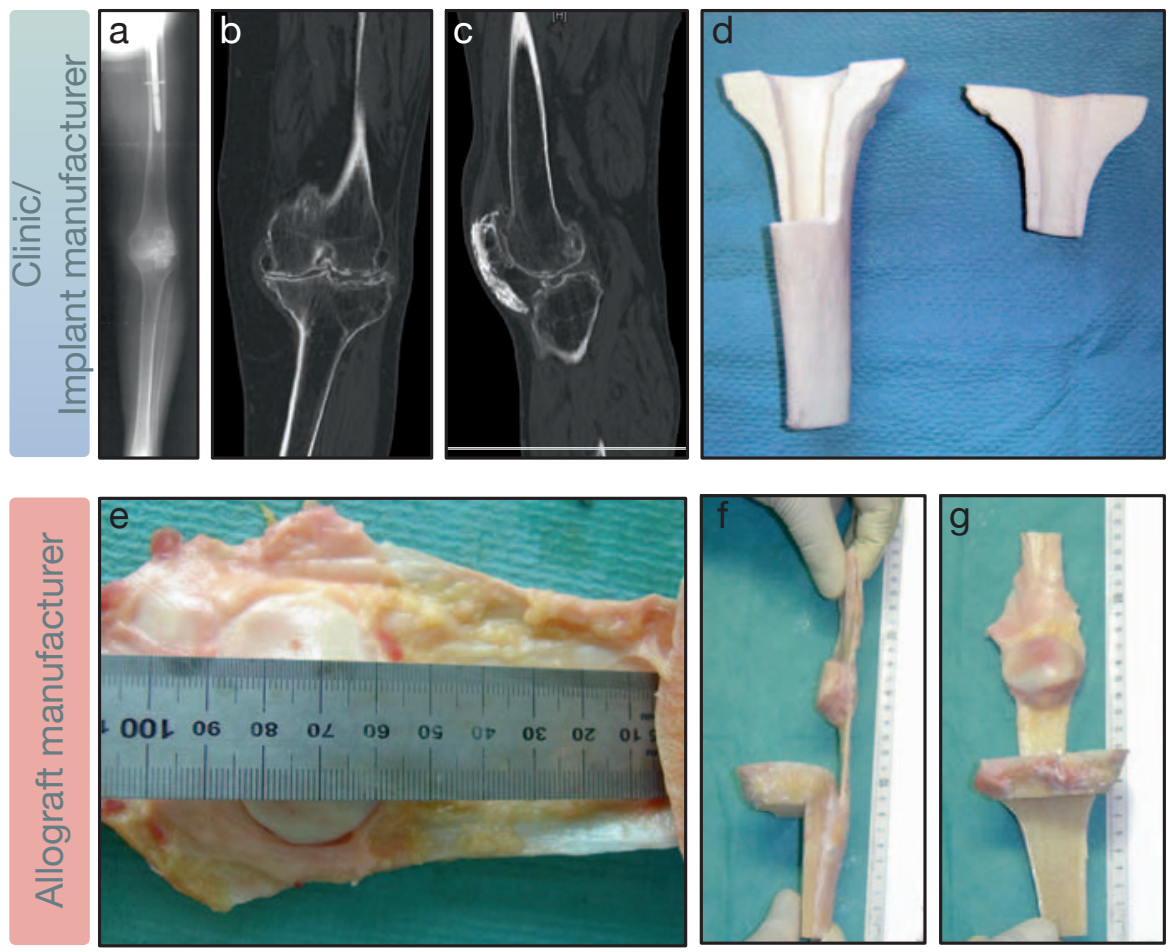

Fig. 4. Total knee arthroplasty: 77 -year-old female patient with proximal femur nail left, traumatic osteoarthritis of the left knee and necrosis of the patellar ligament. a Pre-operative radiograph of the left leg. $\mathbf{b}$ CT-scan: posterior view of the left knee. c CT-scan: lateral view of the left knee. d Representative lesion model and allograft template. e Mensuration of donor tissue in the initial stage of custom allograft production. $\mathbf{f}$ Lateral view of the manufactured custom macro-allograft. g Posterior view of the manufactured custom macro-allograft. h Tibial nail for implant fixation next to the custom macro-allograft. i Surgical situation after resection of the remnants of the patellar ligament and the patella. j Surgical situation post transplantation of the custom allograft held in place by screws, a Kirschner-wire and the tibial component of the implant. $\mathbf{k}-\mathbf{m}$ Postoperative (8 months) X-rays ( $\mathbf{k}$, I posterior and lateral view of the position of the implant, $\mathbf{m}$ sunrise view of the transplanted patella revealing its lateral position).
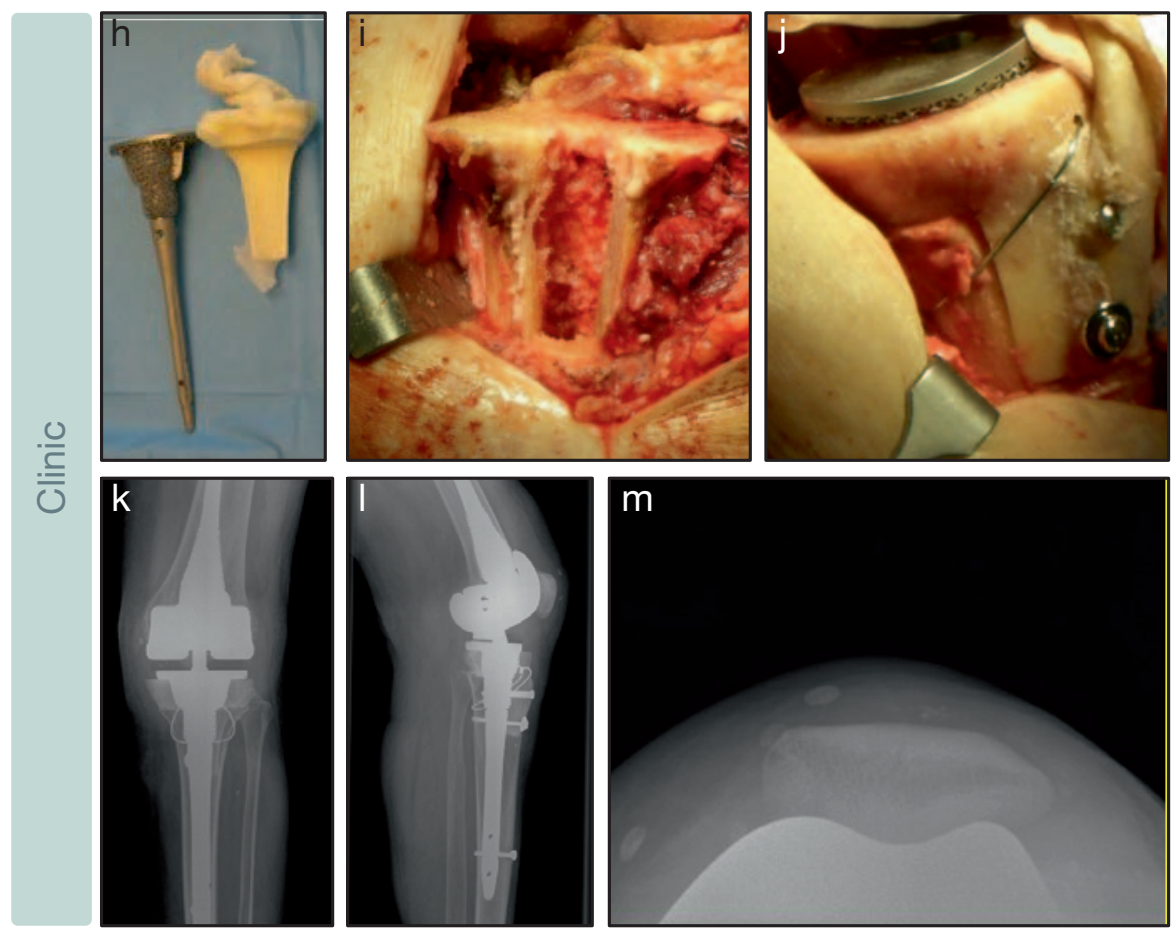

not contra-indicated may be candidates for a combination treatment with a custom implant and an individual allograft when standard, evidencebased treatment options have been depleted.

Once the requirement for a custom implant has been identified, a careful review of anamnesis, imaging as well as clinical and laboratory results is conducted in order to establish whether a custom allograft is also necessary and appropriate. At this early point, although the allograft cannot be specified, it is advisable for the surgeon to contact the allograft manufacturer with a general description of the case so that the allograft manufacturer can start to review released tissues regarding their suitability for manufacturing the necessary component.
Imaging and Lesion Model Construction

$\mathrm{X}$-ray CT data from a single imaging session with constant scale and gantry angle are a pre-requisite for the production of matched implants and grafts. Detailed instructions for this procedure are available from most implant manufacturers. Data for the cases presented in this article were collected on a Somatom Emotion 16 (case 1) and a Somatom Emotion 6 (case 2), both Siemens AG (Munich, Germany). The surgeon supplies such a CT data set to the implant manufacturer where it is used to generate a stereolithographic data file from which a fast-prototype full-scale model is fabricated on a computer-controlled milling machine (fig. 3d,e; 4d). This model is the basis for all further collaboration between clinic, 
implant manufacturer and allograft manufacturer and allows the surgeon to precisely plan the placement of graft, implant, plates and screws [26-31].

\section{Planning for Allograft Manufacture}

Once the implant design has been finalised, the lesion model is passed on to the allograft manufacturer. The allograft manufacturing technicians continuously review tissue released to manufacturing in order to identify candidate material from which a suitable macro-graft can be manufactured. At this stage, discussions between the allograft manufacturer and surgeon focus on the required characteristics of the allograft. The necessary load-bearing properties and any requirements for anchorage are identified. The allograft manufacturer can then define the nature of the required allograft component so that the surgeon may place an order for a custom graft.

\section{Ordering a Custom Allograft (Germany)}

Human tissue transplants are regulated in Germany as medicinal products. There are three recognised active ingredients for bone transplants: Cancellous bone, cortical bone and demineralized bone matrix. Individual marketing authorisations are defined by the active ingredient and the preservation method. Custom macro-allografts are generally manufactured from non-demineralised bone according to the approval for the predominant active ingredient. They may only be manufactured upon written request from a surgeon for a named patient and must be manufactured with the sterilisation, preservation, aseptic processing and packaging methods named in the marketing authorisation for the given active ingredient. However, such a graft must not be in compliance with registered package sizes. Once the surgeon places such an order for the macrograft, the manufacturer can begin fabrication.

\section{Manufacture of a Custom Structural Macro-Graft}

Custom allograft fabrication begins with evaluating donor tissues released to manufacture for suitable structures that meet size and stability requirements. To this end a polyurethane (PU) graft template (fig. $3 \mathrm{f}, \mathrm{g}$ ) is initially generated according to the physical lesion model. The PU model is then used in a selection process for identifying available tissue components that match size and quality criteria. Proximal tibial, proximal and distal femoral components are usually the basis of macro-allografts. Once suitable donor material is identified, the PU model also serves as a template for the final allograft. At this point, a proposal from the allograft manufacturer is sent to the clinic. This proposal details the construction plans for the macro-graft and describes the material selected for manufacture. Once the clinic approves the proposal, manufacturing can begin.

\section{Pre-Sterilisation Manufacture}

The tissue for the allograft is initially processed in a clean, controlled but non-classified (CNC) environment. The material necessary for the graft is dissected and separated. Cancellous bone is delipidised by purging with warm water $\leq 37^{\circ} \mathrm{C}$. Cleaned bone components are then approximately shaped with a band saw and then more precisely shaped with rotary power tools in an iterative process of shaping the component and checking it either against the PU template or for fit in the lesion defect model. Once a satisfactory fit is achieved, the allograft undergoes a final pre-sterilisation process of aqueous rinsing for $16 \mathrm{~h}$.

\section{Sterilisation and Packaging}

Allografts are sterilised by a validated method involving the treatment of the tissues with a solution of $1 \%$ peracetic acid (Wofasteril (AM); Kesla Hygiene AG, Bitterfeld-Wolfen, Germany) / 24\% Ethanol (Berkel AHK Alkoholhandel GmbH and Co. KG, Berlin, Germany) in aqua ad iniectabilia for $4 \mathrm{~h}$ with vigorous shaking at a pressure below 200 mbar [32-37].
After sterilisation the custom allografts are aseptically packaged in double sterile bags (Steriking; Wipack B. V. Medical, Sittard, the Netherlands). The custom allografts are stored in a frozen state at $-40{ }^{\circ} \mathrm{C}$ and are finally sent on dry ice to the recipient via courier.

\section{Transplantation Preparation}

Prior to transplantation, a final consultation is necessary to check that all components fit together in the model. In this context, the most recent images from the patient are also reviewed. It is also necessary to check that the patient is in an appropriate condition for the operation. The likelihood that prolonged general anaesthesia will be necessary and that postoperative complications may arise should be taken into consideration. Patients should therefore have normal blood coagulation parameters as well as adequate cardiac function and are free from infection and likely to be post-operatively compliant, especially in physiotherapy.

\section{Results}

During the last 6 years, a total of 6 ( 2 male and 4 female) patients have been treated with custom manufactured macro-allografts at the Clinic for Accident, Hand und Reconstructive Surgery of the Robert Koch Krankenhaus in Apolda, Germany. During this time, no adverse reactions or events in relation to the macro-allograft prosthesis composite treatment were recorded.

The average time between planning CT and transplantation was $134 \pm 90$ days.

\section{Patient Example 1}

In a 62-year-old male with essential arterial hypertonia, insulin-dependent diabetes mellitus type II and obesity, an initial left-side stage $\mathrm{V}$ coxarthrosis [38] producing severe pain and limiting mobility was diagnosed in 2008. A primary THA was carried out in April 2008. Stem loosening was diagnosed in February 2009, and the femoral component was revised in March 2009. Acetabular component loosening was identified in March 2010. The latter was associated with a fracture of the contra-lateral os sacrum. The acetabular component underwent revision in May 2010 (fig. 3a) with subsequent loosening being diagnosed in October 2011 (fig. 3b). An acute local infection with Propionibacterium acnes and Staphylococcus aureus was diagnosed in November 2011. Complete explantation of the endoprosthesis and replacement with a temporary spacer component was conducted in March 2012.

At this point, initial planning of a 4 th revision began. A requirement for a custom-manufactured allograft-prosthesis composite was identified (fig. $3 \mathrm{~m}$ ). Specifically, the infected acetabulum with a type 6 defect [39] and an associated Paprosky [40] type IV stem defect required a THA with filling of the pelvic defect with a custom manufactured allograft and implantation of customised total hip endoprosthesis.

The computer-generated defect data used to develop a defect-correcting therapeutic strategy are illustrated in figure $3 \mathrm{c}$. Figures $3 \mathrm{~d}$ and $3 \mathrm{e}$ show the lesion model and custom implant fabricated for this treatment. The allograft template manufac- 
tured from polyurethane is depicted in figure $3 \mathrm{f}$. The desired fit and form of the allograft component with respect to the defect and the implant design can be seen in figure $3 \mathrm{~g}$. The size of the allograft component required for this treatment mandated that the component be manufactured from 2 donor tissue blocks. Since the graft would be load-bearing, these two components must interlock in such a way as to prevent their dislocation in the defect. A projection line for the division of the allograft component into 2 interlocking parts can be seen in figure $3 \mathrm{~h}$. The initial machining of one epiphyseal tibial component is depicted in figure $3 \mathrm{i}$. The results of the iterative shaping and fit-checking process are shown in figures $3 \mathrm{j}$ (early comparison of graft and template), $3 \mathrm{k}$ (final) and 31 (final in lesion model). The results of a final intra-operative check of the fit of the allograft component to the implant can be seen in figure $3 \mathrm{~m}$.

Each of the 2 components of the structural allograft was manufactured from a proximal tibial epiphysis from a 36-yearold male donor.

The transplant operation was carried out in August 2012. It was successful and free from implant and transplant-related complications. Figure $3 \mathrm{n}$ shows the post-operative radiograph demonstrating the position of the total custom hip endoprosthesis.

The early post-operative course was normal apart from slightly elevated inflammatory parameters in the first 14 days post operation. The patient could be released from hospital on schedule and at the time of writing (6 weeks post operation) is mobile with crutches. Limb utility has been restored. A misalignment of the centre of rotation and differences in limb length have been corrected.

\section{Patient Example 2}

A 77-year-old female with hypertonia, obesity and a left-sided proximal femur nail presented with traumatic osteoarthritis in the left knee with cystic patellar degeneration, associated necrosis of the patellar ligament and misalignment. The patient also complained of constant pain and required daily analgesic medication (5-6 on the visual analogue scale (VAS)). A maximum walking distance of $500 \mathrm{~m}$ and a knee society score of 58 points were also recorded at this time.

A requirement for a custom total knee endoprosthesis and associated structural allograft was identified. The macro-allograft requirements were: compensation of a major anterior proximal tibial defect, complete replacement of the patellar ligament including patella and provision of a significant distal component of the quadriceps tendon for soft tissue anchorage.

The pre-operative situation is depicted in figures $4 \mathrm{a}(\mathrm{X}$ ray), 4b (CT) and 4c (CT). The resulting lesion model (left) and graft template (right) are shown in figure $4 \mathrm{~d}$. In this case, the primary challenges in tissue matching were associated with the soft tissue components. Figure $4 \mathrm{e}$ depict the process of tissue matching during the manufacture of the required graft, figures $4 \mathrm{f}$ and $4 \mathrm{~g}$ show the final macro-allograft.
This allograft component could be manufactured from a single tibial epiphysis of a 27 -year-old male donor.

The intra-operative situation is represented in figures $4 \mathrm{~h}$ (pre-transplantation, custom tibial implant and matched structural allograft), 4i (intra-operative, tibial defect) and $4 \mathrm{j}$ (post transplantation and implantation, detailing fixation of the allograft component with screws and a tensioned circumferential wire).

The initial post-operative course in this patient was complicated by a local infection with Staphylococcus epidermidis that responded to antibiotic treatment.

Radiographic check-ups demonstrated that the integrity and position of the allograft components was retained throughout the follow-up period. The radiographs in figures $4 \mathrm{k}, 4 \mathrm{l}$ and $4 \mathrm{~m}$ illustrate the situation 8 months post operation. The ideal position of the tibial allograft component can be seen clearly in figure 41 , and the optimal lateral placement of the patella is evident in figure $4 \mathrm{~m}$.

At 18 months post operation, this patient was pain-free $(0$ on the VAS), could walk distances of $2 \mathrm{~km}$ outdoors with a walking stick, was domestically mobile without restrictions or a requirement for walking aids and could flex the knee without pain more than 90 degrees against gravity (knee society score 140).

\section{Discussion}

Our experience suggests that custom macro-allografts to be used in revision surgery in combination with custom endoprosthetic implants can be manufactured with an acceptable quality, within an acceptable time frame and according to the stringent requirements of the German regulatory environment. The mean time between initial CT scan and transplantation was 134 days. The allograft component was available within 100 days of ordering. Whilst this can be acceptable for planned elective revision surgery, it contrasts with the 4-week time frame required to manufacture and release standard allogeneic transplants. A significant block of the approximately 100 days required for release of custom-manufactured macro-allografts is associated with the 'screening' of incoming tissue for suitability for manufacture of specific macro-graft components.

Transplant-related complications, reactions and adverse events have been absent so far.

However, this experience is currently limited to the treatment of 6 patients in a single clinic; so it is not yet possible to quantitatively assess clinical outcomes and benefits. In contrast, bone augmentation with standard allografts in endoprosthetic revision surgery is an established method [41].

Even though extensive re-modelling of structural macroallografts is not to be expected [42], such grafts offer important possibilities with regard to the integration of the graft in host bone. A zone of re-modelling at the interface of well perfused host bone and allograft delivers important stability to 
the graft/implant combination [42]. In one study of proximal femoral allograft-prosthesis composites, union of the host bone and the allograft was achieved in $81.9 \%(59 / 72)$ of the cases [3].

While there is currently an absence of level 1, or 2 evidence about whether the use of custom structural allografts has an effect on the lifespan of endoprosthetic implants, the use of such transplants offers ground for expectation of re-stocking the bone material available for future revisions and can therefore be considered as a prudent measure in terms of long-term results as long as there are no associated significant medical disadvantages.

There are clear short-term advantages associated with the use of custom allografts rather than standard products. When successfully manufactured according to precise anatomical lesion models, the former negate all requirements for intra-operative modification of the component. In addition to ensuring that the operation can proceed as planned without having to improvise for unforeseen fixation requirements and thereby avoiding extra direct costs, this correlates with a reduced requirement for operating theatre time and therefore also reduces indirect costs.

These advantages are in part a consequence of a high level of pre-operative planning and the use of modern tools and technologies including 3D medical modelling and planning software and as such represent a partial shift in terms of planning and responsibility from the surgeon to the manufacturer and from the peri-operative to the pre-operative phase. The necessity for thorough planning by all parties makes regular and effective communication between all parties a prerequisite.

Despite the advantages of the application of custom-manufactured transplants based on CT data, there are some caveats to consider:

i) Inconsistencies between the physical model generated from CT data and the actual anatomical situation in the patient (possibly due to continuing degeneration in the joint, or possibly due to artefacts in the CT dataset being transcribed into the lesion model) may lead to the manufacture of an allograft component that does not fit perfectly. It will therefore usually be expedient to utilise the time available and perform a pre-operative CT scan to ensure the CT data used to produce the physical defect model matches the current defect situation.

ii) Furthermore, even if the CT data and the physical model are accurate and both implant and transplant produce a perfect fit in pre-operative checks, it may nevertheless prove impossible to carry out the operation as planned if all spatial and navigational requirements for placement of components are not given due pre-operative consideration. This is particularly important in cases where large bone grafts require to be placed in difficult to reach anatomical positions.

iii) Occurrence of graft resorption cannot generally be ruled out when large avital allograft components are trans- planted. It is not surprising that in most series a degree of resorption is considered to be evident in radiographic images. However, as long as resorption is limited and marginal and since re-vascularisation of such grafts is usually not extensive, the graft is unlikely to collapse due to loss of mechanical strength during remodelling.

Three retrieval studies in the knee and hip revealed neither re-vascularisation nor resorption [42-44]. However, a metaanalysis by Babis and co-workers [3] evaluated 7 studies analysing the application of allograft-prosthesis composites and calculated the mean level of resorption to be $24.1 \% \pm 14.7 \%$. Even though this fraction covers all levels of detected resorption (mild, medium, severe), this issue should not be neglected.

There is a theoretical risk of disease transmission associated with the use of allografts. All allograft transplants manufactured in Germany are required by law to undergo a validated sterilisation procedure. Tissue transplants manufactured by DIZG undergo a peracetic acid-based sterilisation process validated in co-operation with the Charité Hospital and the Robert Koch Institute (both Berlin, Germany). This process was shown to effectively eliminate model viral and bacterial populations representative of the array of known relevant pathogenic microorganisms [33]. Although established methods of sterilising tissue transplants can have a negative effect on graft remodelling [45], the advantages of sterilisation in terms of safety can legitimately be considered to outweigh potential disadvantages with respect to remodelling in the case of structural macro-allografts. To some extent, a restricted remodelling capacity can be advantageous since loss of mechanical strength in the critical post-operative phase will be limited as a consequence. A non-remodelled graft generally provides adequate mechanical load bearing capacity [42].

\section{Perspectives}

The application of CNC milling technology might improve the precision and production rate of custom allografts. With software that could interpret CT data, recognise anatomical landmarks and envisage intra-operative requirements for placement and navigation, a computer could generate the data required for $\mathrm{CNC}$ milling or fast-prototype fabrication of the graft and delegate the fabrication task to an appropriate machine. The data generated for graft fabrication could also be used to scan donor tissue released to manufacturing in order to identify tissue components suitable for manufacturing the graft. Non-destructive test methods might also conceivably be used to analyse candidate tissue components for their suitability in terms of required biomechanical properties.

Nevertheless, although such automation might enable substantial process refinement, the anatomical knowledge and manufacturing experience of a skilled tissue preparation engineer and the facility for direct and unfiltered communication between this engineer and the orthopaedic surgeon are extremely valuable and should not be disregarded. 


\section{Conclusions}

The use of structural macro-allografts is an alternative to endoprosthetic mega-implants in difficult revision THA or TKA. The process requires elaborate planning and extensive communication, but comes with the benefits of a ready-to-use transplant that fits perfectly and enables the re-stocking of bone material for future surgery. Additional benefits include reduction of operating theatre time, reduction of blood loss and, when compared with use of autologous bone for augmentation, absence of harvest site morbidity. Our manufacturing process for custom allograft is still associated with a requirement for skilled and precise manual labour. The efficiency of the process could be improved by the application of state-of-the-art computer-controlled milling technology.

\section{Acknowledgements}

The authors would like to thank the implant manufacturers who in all cases provided the physical lesion models used to manufacture the allografts. The competent and friendly support provided by the personnel of Waldemar LINK GmbH and Co. KG, Hamburg, Germany is particularly appreciated.

\section{Disclosure Statement}

The authors disclose the following financial interests:

UH, MDS and JCB are employees of the German Institute for Celland Tissue Replacement.

The Robert Koch Hospital received financial support from the German Institute for Cell- and Tissue Replacement.

\section{References}

1 Sporer SM: How to do a revision total hip arthroplasty: revision of the acetabulum. Instr Course Lect 2012;61:303-311.

2 Kobayashi S, Saito N, Horiuchi H, Iorio R, Takaoka K: Poor bone quality or hip structure as risk factors affecting survival of total-hip arthroplasty. Lancet 2000;355:1499-1504.

-3 Babis GC, Sakellariou VI, O'Connor MI, Hanssen AD, Sim FH: Proximal femoral allograft-prosthesis composites in revision hip replacement: a 12-year follow-up study. J Bone Joint Surg Br 2010;92:349_ 355.

4 Boscainos PJ, Kellett CF, Maury AC, Backstein D, Gross AE: Management of periacetabular bone loss in revision hip arthroplasty. Clin Orthop Relat Res 2007;465:159-165.

$\checkmark 5$ Whiteside LA, Bicalho PS: Radiologic and histologic analysis of morselized allograft in revision total knee replacement. Clin Orthop Relat Res 1998;357:149-156.

6 Clatworthy MG, Gross AE: The allograft prosthetic composite: when and how. Orthopedics 2001 24:897-898.

7 Bert JM: Custom total hip arthroplasty. J Arthroplasty 1996;11:905-915.

8 Nysted M, Benum P, Klaksvik J, Foss O, Aamodt A: Periprosthetic bone loss after insertion of an uncemented, customized femoral stem and an uncemented anatomical stem. Acta Orthop 2011;82: 410-416.

$\checkmark 9$ Flecher X, Pearce O, Parratte S, Aubaniac J-M, Argenson J-N: Custom cementless stem improves hip function in young patients at 15-year followup. Clin Orthop Relat Res 2010;468:747-755.

10 Sewell MD, Hanna SA, Muirhead-Allwood SK, Cannon SR, Briggs TWR: Custom cementless THA in patients with skeletal dysplasia results in lower apparent revision rates than other types of femoral fixation. Clin Orthop Relat Res 2011;469: 1406-1412.

11 Daines BK, Dennis DA: Management of bone defects in revision total knee arthroplasty. J Bone Joint Surg 2012;94:1131-1139.

12 Qiu YY, Yan CH, Chiu KY, Ng FY: Review article: Treatments for bone loss in revision total knee arthroplasty. J Orthop Surg (Hong Kong) 2012;20 78-86.
13 Sporer SM: How to do a revision total hip arthroplasty: revision of the acetabulum. J Bone Joint Surg 2011;93:1359-1366.

14 Engh GA, Parks NL: The management of bone defects in revision total knee arthroplasty. Instr Course Lect 1997;46:227-236.

15 Abdeen A, Healey JH: Allograft-prosthesis composite reconstruction of the proximal part of the humerus: surgical technique. J Bone Joint Surg 2010;92:188-196

16 Gilbert NF, Yasko AW, Oates SD, Lewis VO, Cannon CP, Lin PP: Allograft-prosthetic composite reconstruction of the proximal part of the tibia. an analysis of the early results. J Bone Joint Surgery 2009;91:1646-1656.

17 Serra C, Delattre O, Dintimille H, Dib C, Rouvillain JL, Catonne Y: Allograft-prosthesis composite arthroplasty for posttraumatic floating elbow (in French). Rev Chir Orthop Reparatrice Appar Mot 2006;92:269-274.

18 Mansat P, Adams RA, Morrey BF: Allograft-prosthesis composite for revision of catastrophic failure of total elbow arthroplasty. J Bone Joint Surg Am 2004:86A:724-735

19 Amirfeyz R, Stanley D: Allograft-prosthesis composite reconstruction for the management of failed elbow replacement with massive structural bone loss: a medium-term follow-up. J Bone Joint Surg Br 2011:93:1382-1388.

20 Abdeen A, Hoang BH, Athanasian EA, Morris CD, Boland PJ, Healey JH: Allograft-prosthesis composite reconstruction of the proximal part of the humerus. Functional outcome and survivorship. J Bone Joint Surg 2009;91:2406-2415.

21 Zehr RJ, Enneking WF, Scarborough MT: Allograft-prosthesis composite versus megaprosthesis in proximal femoral reconstruction. Clin Orthop Relat Res 1996;322:207-223.

22 Woodgate IG, Saleh KJ, Jaroszynski G, Agnidis Z, Woodgate MM, Gross AE: Minor column structural acetabular allografts in revision hip arthroplasty. Clin Orthop Relat Res 2000;371:75-85.

23 Haddad FS, Spangehl MJ, Masri BA, Garbuz DS, Duncan CP: Circumferential allograft replacement of the proximal femur. A critical analysis. Clin Orthop Relat Res 2000;371:98-107.
24 Haddad FS, Garbuz DS, Masri BA, Duncan CP: Structural proximal femoral allografts for failed total hip replacements: a minimum review of five years. J Bone Joint Surg Br 2000;82:830-836.

25 Hoeffel DP, Rubash HE: Revision total knee arthroplasty: current rationale and techniques for femoral component revision. Clin Orthop Relat Res 2000;380:116-132.

26 Mittelmeier W, Peters P, Ascherl R, Gradinger R: [apid prototyping. Construction of a model in the preoperative planning of reconstructive pelvic interventions (in German). Orthopäde 1997;26:273279.

27 Bruns J, Habermann CR, Rüther W, Delling D The use of CT derived solid modelling of the pelvis in planning cancer resections. Eur J Surg Oncol $2010 ; 36: 594-598$

28 Esses SJ, Berman P, Bloom AI, Sosna J: Clinical applications of physical 3D models derived from MDCT data and created by rapid prototyping. AJR Am J Roentgenol 2011;196:W683-688.

29 Rengier F, Mehndiratta A, Tengg-Kobligk von H, Zechmann CM, Unterhinninghofen R, Kauczor $\mathrm{H}-\mathrm{U}$, et al: 3D printing based on imaging data: review of medical applications. Int J Comput Assist Radiol Surg 2010;5:335-341.

30 Lorenz C, Krahnstöver N: Generation of pointbased 3D statistical shape models for anatomical objects. Comp Vis Imag Under 2000;77:175-191.

31 Webb PA: A review of rapid prototyping (RP) techniques in the medical and biomedical sector. $\mathrm{J}$ Med Eng Technol 2000;24:149-153.

32 Pruss A, Göbel UB, Pauli G, Kao M, Seibold M, Mönig H-J, et al: Peracetic acid-ethanol treatment of allogeneic avital bone tissue transplants - a reliable sterilization method. Ann Transplant 2003;8: 34-42.

33 Pruss A, Baumann B, Seibold M, Kao M, Tintelnot $\mathrm{K}$, von Versen R, et al: Validation of the sterilization procedure of allogeneic avital bone transplants using peracetic acid-ethanol. Biologicals 2001;29: 59-66.

34 Von Versen R, Starke R: The peracetic acid/low pressure cold sterilization - a new method to sterilize corticocancellous bone and soft tissue. Z Exp Chir Transplant Kunstliche Organe 1989;22:18-21. 
35 Starke R, Hackensellner HA, von Versen R: Experimental studies of the sterilization of transplantation material with peracetic acid (in German). Z Exp Chir Transplant Kunstliche Organe 1984;17: 254-258.

36 Brosig H, Jacker H-J, Borchert H-H, Kalus U, Dörner T, von Versen R, et al: Sufficient penetration of peracetic acid into drilled human femoral heads. Cell Tissue Banking 2005:6:231-237.

-37 Pruss A, Kao M, Kiesewetter H, von Versen R, Pauli G: Virus safety of avital bone tissue transplants: evaluation of sterilization steps of spongiosa cuboids using a peracetic acid-methanol mixture. Biologicals $1999 ; 27: 195-201$
Kellgren JH, Lawrence JS: Radiological assessment of osteo-arthrosis. Ann Rheum Dis 1957;16: 494-502.

39 Bettin D, Katthagen B-D: The German Society of Orthopedics and Traumatology classification of bone defects in total hip endoprostheses revision operations (in German). Z Orthop Ihre Grenzgeb 1997;135:281-284.

40 Aribindi R, Barba M, Solomon MI, Arp P, Paprosky W: Bypass fixation. Orthop Clin North Am 1998;29:319-329.

41 Pruss A, Knaepler H, Katthagen B-D, Frommelt L, European Union: Consequence of European Directive 2004/23/EC for bone banks in Germany (in German). Orthopäde 2005;34:1160, 1162-1166, 1168.
42 Parks NL, Engh GA: The Ranawat Award. Histology of nine structural bone grafts used in total knee arthroplasty. Clin Orthop Relat Res 1997;345: 17-23.

43 Enneking WF, Mindell ER: Observations on massive retrieved human allografts. J Bone Joint Surg Am 1991;73:1123-1142.

44 Hooten JP, Engh CA, Heekin RD, Vinh TN: Structural bulk allografts in acetabular reconstruction. Analysis of two grafts retrieved at post-mortem. J Bone Joint Surg Br 1996;78:270-275.

45 McAllister DR, Joyce MJ, Mann BJ, Vangsness CT: Allograft update: the current status of tissue regulation, procurement, processing, and sterilization. Am J Sports Med 2007;35:2148-2158. 